\title{
Depression, Anxiety and Stress among Swedish University Students Before and During Six Months of the COVID-19 Pandemic: A Cohort Study.
}

Fred Johansson ( $\square$ fred.johansson@shh.se )

Sophiahemmet University https://orcid.org/0000-0001-9717-0935

Pierre Côté

Ontario Tech University

Sheilah Hogg-Johnson

Toronto University

Ann Rudman

Karolinska Institutet

Lena W. Holm

Karolinska Institutet

Margreth Grotle

Oslo Metropolitan Univeristy

Irene Jensen

Karolinska Institutet

Tobias Sundberg

Sophiahemmet University

Klara Edlund

Karolinska Institutet

Eva Skillgate

Sophiahemmet University

\section{Research Article}

Keywords: Depression, Anxiety, Stress, Mental Health, COVID-19, Coronavirus, Students, Sweden

Posted Date: January 5th, 2021

DOl: https://doi.org/10.21203/rs.3.rs-70620/v2

License: (c) (i) This work is licensed under a Creative Commons Attribution 4.0 International License.

Read Full License 


\section{Abstract}

The COVID-19 pandemic has a profound effect on societies and citizens worldwide, raising concerns about potential mental health impacts. We aimed to describe trajectories of depression, anxiety, and stress symptoms during the COVID-19 outbreak compared to before, and determine if trajectories were modified by pre-pandemic loneliness, poor sleep quality and mental health problems. We conducted a cohort study with 1836 Swedish university students entering before the onset of the pandemic, March 13, 2020, with follow-ups within three (FU1) and six months (FU2) of the outbreak. Generalized Estimating Equations were used to estimate mean differences in symptom levels over time-periods, and to estimate potential effect modifications. We found small differences in mean levels of the Depression, Anxiety and Stress Scale (DASS-21) over time. Compared to before the pandemic, depression increased by 0.25 points of 21 ( $95 \% \mathrm{Cl}: 0.04$ to 0.45 ) at FU1 and decreased by $-0.75 / 21$ (95\% Cl: -0.97 to -0.53 ) at FU2. Anxiety decreased from baseline to FU1 by $-0.09 / 21$ (95\% Cl: -0.24 to 0.07 ) and by $-0.77 / 21$ (95\% Cl: -0.93 to $-0.61)$ to FU2. Stress decreased from baseline to FU1 by $-0.30 / 21$ (95\% Cl: -0.52 to -0.09$)$ and by $-1.32 / 21$ ( $95 \% \mathrm{Cl}:-1.55$ to -1.09$)$ to FU2. Students with pre-pandemic loneliness, poor sleep quality and prepandemic mental health problems did not show worse trajectories of mean mental health symptoms. In conclusion, symptom levels were relatively stable during the first three months of the pandemic, while there was a slight decrease during the summer months, probably due to seasonality effects.

\section{Background}

The COVID-19 pandemic has had a profound impact on societies and the daily lives of citizens globally. In a call for action, Holmes et al. (1) raised concern about the potential detrimental effects that the pandemic might have on mental health and urgently called for research to evaluate the impact of the pandemic. With repeated reports of high levels of mental health problems among university students prior to the COVID-19 pandemic $(2,3)$, it is of utmost importance to describe the impact of the pandemic on the mental health of university students.

An ongoing "living" systematic review of the current longitudinal studies found that most studies reported small to negligible increases of mental health symptoms in the general population (4). In contrast, decreasing levels of depression and anxiety from the beginning of lock-downs was recently reported in a large UK cohort (5). For university students specifically, some studies indicates that depression and anxiety has increased during COVID-19 $(6,7)$, while some have found slight decreases (8).

The spread of COVID-19 in Sweden accelerated rapidly from the beginning of March 2020. On March $13^{\text {th }}$ the Public Health Agency of Sweden declared that the spread of COVID-19 had entered a new more intense phase (9). Four days later, on March $17^{\text {th }}$ universities cancelled all campus-based education and switched to online education (10). Sweden has had high COVID-19 mortality, and the government's strategy to contain the spread of the virus has received international attention. Like in many other countries, Sweden's public health strategy to control the spread of the virus focused on promoting physical distancing. Unlike in many other countries, no enforced general lockdowns have yet been issued. 
Nevertheless, reductions in social contacts, mobility and travelling were strongly encouraged by authorities, and daily life of Swedish citizens was highly affected by the pandemic. Population-based surveys indicate that most of the Swedish population adhered to these recommendations during the spring of $2020(11)$.

Given Sweden's unique strategy, there is an urgent need to conduct longitudinal evaluations of the mental health impact of the COVID-19 pandemic. University students, who show high levels of mental health problems compared to general populations (3), are a potential at-risk group during the COVID-19 pandemic, with students with pre-pandemic loneliness, poor sleep and poor mental health possibly being at higher risk.

The impact of physical distancing and loneliness on mental health during the COVID-19 pandemic has been expressed as a key concern (12). Loneliness is a predictor for the development of depression (13), and it is associated with worse prognosis for depressed individuals (14). Living alone has been reported as a risk factor for depression and anxiety during the COVID-19 pandemic (15). Similarly, poor sleep quality is a prevalent and increasing problem among university students (16), and it is associated with depression, anxiety, and stress during the COVID-19 pandemic in a general population (17).

Physiologically, poor sleep quality impairs emotional regulation and increases affective reactivity (18), and is associated with increased negative emotions following disruptive events (19). As highlighted by Yao (20), individuals with pre-existing mental health problems may be at risk of worsening symptoms during the COVID-19 pandemic. Two cross-sectional studies suggest that increased symptoms of anxiety, symptoms of eating disorder and other psychiatric symptoms among psychiatric patients during the COVID-19 pandemic (15). This may be significant also for individuals with minor mental health problems because they are at risk for developing more severe problems $(21,22)$.

Our primary objective was to describe the trajectories of depression, anxiety, and stress symptomatology in university students in Stockholm before and during the first six months of the COVID-19 pandemic. Our secondary aim was to determine if trajectories of depression, anxiety and stress over time were modified by pre-pandemic loneliness, poor sleep quality and mental health problems. We hypothesized that symptoms of depression, anxiety, and stress would increase during the COVID-19 pandemic, and that the trajectories over time would be worse for students with loneliness, poor sleep quality and pre-pandemic mental health problems.

\section{Method}

\section{Design and study population}

A cohort study of university students in Stockholm, Sweden before the outbreak and during COVID-19 was conducted. The study is nested within a larger on-going dynamic cohort study of university students: the Sustainable University Life (SUN-study) (http://clinicaltrials.gov/ ID: NCT04465435). 
Participants came from six selected universities in Stockholm, covering medical, economic technical and sport science educations (Table 1). Full-time undergraduate students with at least one year left to complete their degree were eligible for inclusion in the study. Data collection in the SUN-study started in August 2019 and will be ongoing until November 2021. Only participants completing their baseline questionnaire before March 13, 2020 were included in this study.

\section{Data collection}

Students received information about the study through in-class presentations by study staff and were provided with access links to the study questionnaire via e-mail. Information about the study was also given in relevant social media channels (e.g., student union social media channels), and at on-campus information sites. Included students were followed with web surveys every three months over one year. Participants not responding to the follow-up surveys received reminders by email, phone text-message and one phone call over the following month. The study was approved by the Swedish Ethical Review Authority (reference number: 2019-03276, 2020-01449), and informed consent was provided by all participants electronically.

\section{Follow-up}

The collected data was divided into three time-periods: before the pandemic (August 19, 2019 to March 13, 2020), follow-up period 1 (FU1; March 14 to June 15, 2020) and follow-up period 2 (FU2; June 16 to September 10, 2020) (Figure 1, eFigure 1). The date marking the start of the pandemic, March 13, is the date that the Public Health Agency of Sweden declared that Sweden entered a new phase in the pandemic (9). Four days later, March 17, Sweden closed all on-campus education on universities switching to on-line education. The cut-point for FU2, June 15, was made since most university semesters had ended by then (eFigure 1).

\section{Outcomes}

Symptoms of depression, anxiety, and stress were measured with the short-form Depression, Anxiety and Stress Scale (DASS-21) (23) at each time-period. DASS-21 consists of 21 items rated on a 4-point scale ranging from 0 (Did not apply to at all) to 3 (Applied to me very much, or most of the time). Scores for the depression, anxiety and stress subscales are the sum of the 7 items in each subscale, ranging from 0-21 with higher scores indicating more severe symptoms. DASS-21 has good psychometric properties, with convergent validity for all subscales, and Cronbach's a of 0.77-0.92 for the three subscales (24).

\section{Exposures}

Pre-pandemic mental health problems was classified as scoring above the cut-offs for moderate symptom levels on any of the three subscales ( $\geq 7$ on the depression subscale or $\geq 6$ on the anxiety subscale or $\geq 10$ on the stress scale) (25) on DASS-21 at baseline. These cut-offs are slightly above the cut-off point found to separate normal population from an outpatient psychiatric population (26) 
Loneliness before the pandemic was measured using the UCLA Three-Item Loneliness Scale (27), consisting of three items rated from 1 (Hardly ever) to 3 (Often). The score of the scale is the sum of the three items. In accordance with previous research, we used a cut-off of $\geq 6 / 9$ to define loneliness (28). The scale has acceptable internal consistency (Cronbach's $a=0.72)$ and high correlation $(r=0.82)$ with the 20 item Revised UCLA Loneliness Scale (27).

Sleep quality before the pandemic was measured using the Pittsburgh Sleep Quality Index (PSQI) (29). The scale consists of 19 items covering seven components of sleep with scores from 0-3. The global score is a sum of the components scores, ranging from 0-21. A global score of $>5 / 21$ was used to classify poor sleep quality. This cut-off has shown a sensitivity of $89.6 \%$ and a specificity of $86.5 \%$ for differentiating between good and poor sleepers (30). The PSQI has adequate internal consistency (Cronbach's $a=0.82)$ and test-retest reliability $(r=0.82)$ over one month (30).

\section{Adjustments}

The statistical models including the exposures were adjusted for gender and age, which were selected a priori based on previous literature.

\section{Statistical analyses}

We used Generalized Estimating Equations (GEE) to model mental health symptoms during three time periods. GEE models treat correlation between observations from the same individual as nuisance parameters and provide estimates of the marginal population mean of the outcome. Our data was not normally distributed, which was one reason for choosing GEE since the model do not rely on the assumption of normally distributed outcome measures or the normality of residuals. We built three separate models, one each for symptoms of depression, anxiety, and stress, to assess overall mean differences in symptoms over the three time periods. These models included only time-period as the predictor. Since the models evaluated mean differences between time-periods for the full group, no covariates were used in these models. All GEE models, including the models described below, were specified with exchangeable working correlation structures, robust sandwich variance estimators and gaussian link functions.

Subsequently nine separate models were fitted to assess the differences in the trajectories over time by exposure levels. We dichotomized our exposures (loneliness, poor sleep quality or pre-pandemic mental health problems), into exposed and non-exposed groups. An interaction term between exposure and timeperiod was included, letting the differences in mean symptom level between exposed and non-exposed vary over time, giving an estimate of the difference-in-difference between mean symptom levels among exposed/non-exposed over time. These models were adjusted for age and gender.

Sensitivity analyses were conducted to examine the possible attrition bias by performing complete caseanalyses (using data from participants who provided complete follow-up). We further conducted a sensitivity analyses in a sample of 496 participants followed before the pandemic, from August- 
September 2019 to November 2019-January 2020. This was done to compare the trajectories of exposed and unexposed groups during the pandemic to those of an earlier time-period (eFigure 2). Graphs (Figure 3 and eFigure 2) were compared by ocular inspection.

All analyses were performed using RStudio version 1.2.5001, the packages 'geepack' and 'emmeans' were used to perform GEE analyses, and to derive estimated marginal means from the models.

Mean imputation by the individual scale means was used to handle missing data on the PSQI that arised due to initial technical problems with the web survey. Three items of the scale were missing $(5 b, 5 f$ and 5j) for the first 512 included participants. No other variables on any scales had missing values.

\section{Results}

We invited 6681 students to participate and 1836 (27\%) consented between August 192019 and March 13,2020 . Of those, $74 \%(n=1364)$ provided follow-up data during the first follow-up period and $60 \%$ $(n=1095)$ provided during the second follow-up period (Figure 1, eFigure 1). baseline, the mean age was 26.5 years, $73 \%$ were female, and $80 \%$ were born in Sweden (Table 1 ).

Table 1. Participants baseline characteristics for all and for students only participating in period 1 and 2 respectively. 


\begin{tabular}{|c|c|c|c|}
\hline & $\begin{array}{r}\text { All } \\
\text { participants } \\
(\mathrm{n}=1836)\end{array}$ & $\begin{array}{r}\text { Participants followed at follow-up } \\
\text { period } 1(\mathrm{n}=1364)\end{array}$ & $\begin{array}{r}\text { Participants followed at follow-up } \\
\text { period } 2(\mathrm{n}=1095)\end{array}$ \\
\hline DASS-21 Depression, mean (SD) & $4.6(4.8)$ & $4.6(4.6)$ & $4.3(4.5)$ \\
\hline DASS-21 Anxiety, mean (SD) & $3.2(3.5)$ & $3.1(3.5)$ & $3.0(3.3)$ \\
\hline DASS-21 Stress, mean (SD) & $6.5(4.6)$ & $6.5(4.6)$ & $6.3(4.6)$ \\
\hline Age, mean (SD) & $26.5(6.8)$ & $26.8(7.0)$ & $27.0(7.1)$ \\
\hline Females, n (\%) & $1358(73 \%)$ & $1033(76 \%)$ & $837(76 \%)$ \\
\hline \multicolumn{4}{|l|}{ Type of education, n (\%) } \\
\hline Medical & 1596 (87\%) & $1204(88 \%)$ & $974(89 \%)$ \\
\hline Economics & 119 (7\%) & 75 (6\%) & $51(5 \%)$ \\
\hline Technical & $80(4 \%)$ & $54(4 \%)$ & $43(4 \%)$ \\
\hline Sports science & $41(2 \%)$ & $31(2 \%)$ & $27(2 \%)$ \\
\hline Lonely, n (\%) & $696(37 \%)$ & $506(37 \%)$ & 399 (36\%) \\
\hline $\begin{array}{l}\text { Moderate mental health problems, } \\
\text { n (\%) }\end{array}$ & 721 (39\%) & $533(39 \%)$ & $406(37 \%)$ \\
\hline Poor sleep quality, n (\%) & $1024(60 \%)$ & $764(56 \%)$ & $586(54 \%)$ \\
\hline \multicolumn{4}{|l|}{ Year of Study, n (\%) } \\
\hline $1^{\text {st }}$ & 910 (50\%) & $624(46 \%)$ & $490(45 \%)$ \\
\hline $2^{\text {nd }}$ & $253(14 \%)$ & $204(15 \%)$ & $163(15 \%)$ \\
\hline $3^{\text {rd }}$ & 306 (16\%) & $235(17 \%)$ & $196(18 \%)$ \\
\hline Masters & 367 (20\%) & $301(22 \%)$ & $246(23 \%)$ \\
\hline $\begin{array}{l}\text { At least one parent with university } \\
\text { education, } \mathrm{n}(\%)\end{array}$ & $1300(70 \%)$ & 970 (71\%) & $778(71 \%)$ \\
\hline \multicolumn{4}{|l|}{ Country of Origin, n (\%) } \\
\hline Sweden & 1489 (80\%) & $1133(83 \%)$ & $908(83 \%)$ \\
\hline Scandinavia & 91 (5\%) & $67(5 \%)$ & $58(5 \%)$ \\
\hline Europe & $88(5 \%)$ & $45(4 \%)$ & $45(4 \%)$ \\
\hline Outside Europe & $168(9 \%)$ & $84(8 \%)$ & $84(8 \%)$ \\
\hline
\end{tabular}

We compared the symptom levels during FU1 and FU2 to baseline levels, on the DASS-21 scale, ranging from 0-21 points for each subscale. Mean depressive symptom levels were $0.25 / 21$ (95 \% Cl: 0.04 to 0.45 ) points higher during FU1 and -0.75/21, (95 \% Cl: - 0.97 to -0.53) points lower during FU2. Mean anxiety levels were $-0.09 / 21$ (95 \% Cl: -0.24 to 0.07) points lower during FU1, and -0.77/21 (95 \% Cl: -0.93 to -0.61) points lower during FU2. Mean stress symptom levels were $-0.30 / 21(95 \%$ Cl: -0.52 to -0.09$)$ points lower during FU1 and -1.32/21 (95\% Cl: -1.55 to -1.09) points lower during FU2, compared to baseline levels (Table 2, Figure 2). The estimates for differences between time-periods from the complete-case sensitivity analyses were with-in 0.13 points from the original estimates (eTable 1).

The participants exposed to pre-pandemic loneliness, poor sleep quality and mental health problems all had higher mean levels of depression, anxiety, and stress at baseline, before the pandemic (Table 2, Figure 3). At FU1 and FU2, during the COVID-19 pandemic, mean differences between the exposed and unexposed were all smaller than at baseline, with none of the confidence intervals spanning zero (Table 2 , Figure 3) 
The difference-in-difference estimates from the complete-case sensitivity analyses were all with-in 0.21 points from the original analyses, all in the same directions as in the main analyses (eTable 1).

Table 2. GEE-model coefficients on mean level depression, anxiety, and stress symptoms over the three time-periods.

\begin{tabular}{|c|c|c|c|}
\hline & $\begin{array}{l}\text { Depression } \\
\text { Coefficient (95\% CI) }\end{array}$ & $\begin{array}{l}\text { Anxiety } \\
\text { Coefficient (95\% CI,) }\end{array}$ & $\begin{array}{l}\text { Stress } \\
\text { Coefficient (95\% CI) }\end{array}$ \\
\hline \multicolumn{4}{|l|}{ Model with only time-periods } \\
\hline Intercept & $4.64(4.42$ to 4.85$)$ & 3.15 (2.99 to 3.31$)$ & $6.51(6.30$ to 6.72$)$ \\
\hline FU1 & $0.25(0.04$ to 0.45$)$ & $-0.09(-0.24$ to 0.07$)$ & $-0.30(-0.52$ to -0.09$)$ \\
\hline FU2 & $-0.75(-0.97$ to -0.53$)$ & $-0.77(-0.93$ to -0.61$)$ & $-1.32(-1.55$ to -1.09$)$ \\
\hline \multirow{2}{*}{\multicolumn{4}{|c|}{$\begin{array}{l}\text { Model with loneliness and time-period } \\
\text { Intercept }\end{array}$}} \\
\hline & & & \\
\hline Loneliness & 3.74 (3.02 to 4.46$)$ & 2.34 (1.79 to 2.89$)$ & 4.59 (3.83 to 5.35$)$ \\
\hline FU1 & $4.22(3.77$ to 4.66$)$ & $2.34(1.79$ to 2.89$)$ & $3.21(2.80$ to 3.63$)$ \\
\hline FU2 & $0.55(0.32$ to 0.79$)$ & $0.16(-0.03$ to 0.33$)$ & $-0.02(-0.28$ to 0.23$)$ \\
\hline Loneliness * FU1 & $-0.29(-0.54$ to -0.04$)$ & $-0.43(-0.61$ to -0.26$)$ & $-1.14(-1.41$ to -0.87$)$ \\
\hline \multirow[t]{2}{*}{ Loneliness * FU2 } & $-0.79(-1.23$ to -0.34$)$ & $-0.65(-0.98$ to -0.31$)$ & $-0.76(-1.22$ to -0.30$)$ \\
\hline & $-1.23(-1.71$ to -0.74$)$ & $-0.90(-1.27$ to -0.54$)$ & $-0.50(-1.01$ to 0.00$)$ \\
\hline \multicolumn{4}{|c|}{ Model with sleep quality and time -period } \\
\hline \multicolumn{4}{|c|}{ Intercept } \\
\hline Poor sleep quality & $3.31(2.58$ to 4.04$)$ & $1.94(1.39$ to 2.49$)$ & 3.85 (3.10 to 4.61$)$ \\
\hline FU1 & $3.83(3.45$ to 4.21$)$ & $2.45(2.17$ to 2.74$)$ & $3.76(3.39$ to 4.61$)$ \\
\hline FU2 & 0.57 (0.31 to 0.83$)$ & $0.20(-0.00$ to 0.39$)$ & $0.06(-0.25$ to 0.37$)$ \\
\hline Poor sleep quality* FU 1 & $-0.22(-0.47$ to 0.03$)$ & $-0.34(-0.53$ to -0.15$)$ & $-0.80(-1.10$ to -0.50$)$ \\
\hline \multirow[t]{2}{*}{ Poor sleep quality* FU2 } & $-0.58(-0.98$ to -0.18$)$ & $-0.51(-0.81$ to -0.21$)$ & $-0.68(-1.11$ to -0.26$)$ \\
\hline & $-0.98(-1.41$ to -0.55$)$ & $-0.75(-1.07$ to -0.44$)$ & $-0.99(-1.44$ to -0.53$)$ \\
\hline \multicolumn{4}{|c|}{ Model with PPMHP and time-period } \\
\hline \multicolumn{4}{|l|}{ Intercept } \\
\hline PPMHP & 2.12 (1.55 to 2.69$)$ & $1.10(0.65$ to 1.54$)$ & 2.73 (2.10 to 3.35$)$ \\
\hline FU1 & $6.90(6.52$ to 7.27$)$ & $4.58(4.28$ to 4.88$)$ & $6.59(6.26$ to 6.92$)$ \\
\hline FU2 & $1.15(0.94$ to 1.35$)$ & $0.51(0.36$ to 0.66$)$ & $0.58(0.34$ to 0.81$)$ \\
\hline PPMHP * FU1 & $0.32(0.11$ to 0.53$)$ & $0.04(-0.10$ to 0.18$)$ & $-0.32(-0.55$ to -0.08$)$ \\
\hline \multirow[t]{2}{*}{ PPMHP * FU2 } & $-2.30(-2.74$ to -1.86$)$ & $-1.54(-1.88$ to -1.20$)$ & $-2.28(-2.73$ to -1.82$)$ \\
\hline & $-2.78(-3.28$ to -2.28$)$ & $-2.12(-2.48$ to -1.75$)$ & $-2.63(-3.14$ to -2.12$)$ \\
\hline
\end{tabular}

All models, except the ones with only time as predictor, were adjusted for gender (female vs male and other) and age (continuous scale). FU1: First follow-up period, FU2: Second follow-up period, PPMHP: Pre-Pandemic Mental Health Problems.

\section{Discussion}

We investigated differences in symptoms of depression, anxiety, and stress in Swedish university students from before outbreak of COVID-19, during the first months of the pandemic when the virus was spreading rapidly (March 14 to June 15, 2020) and during the coming three summer months (June 16 to September 10. 2020) when the spread of the virus had decreased but by no means stopped (eFigure 1). The results did not support our hypothesis that overall mean levels of depression, anxiety and stress symptoms would be higher during the COVID-19 pandemic compared to before. During the early phase (FU1) of the pandemic mean depressive symptoms increased slightly, while small decreases were found for both mean anxiety and stress levels. For anxiety, the confidence interval spanned zero making the direction of this difference uncertain. During FU2 mean levels of depression, anxiety, and stress 
symptoms were all lower compared to baseline levels. Overall, our results showed no substantial increases in mean levels of depression, anxiety, or stress symptoms in our sample of Swedish university students during the first six months of the COVID-19 pandemic compared to before the pandemic. Symptom levels were relatively stable during the first three months of the pandemic, while there was a decrease during the summer months. This decrease was probably due the seasonality effects and change in everyday life brought about by the summer vacations. Nevertheless, these group level changes are small in relation to what would be considered clinically relevant change on an individual level (26).

We further hypothesized that groups of students who were lonely, had poor sleep quality or pre-pandemic mental health problems would experience worse trajectories of symptoms of depression, anxiety, and stress over the first months of the pandemic. Our results did not support this hypothesis either. As expected, the exposed groups had higher mean levels of mental health symptoms at all time-periods. However, the mean difference in symptoms of depression, anxiety, and stress between exposed and nonexposed all decreased over the first months of the pandemic for all the exposures. None of the confidence intervals for these difference-in-differences over time spanned zero. This indicates favorable trajectories of mental health symptoms for the exposed compared to the non-exposed groups. These patterns of decreased differences between exposed and non-exposed groups over time is similar to what can be seen among students followed in this cohort during the fall of 2019, before the pandemic (Figure 3, eFigure 2). This indicates that the exposed groups trajectories of mental health was not considerably different during the pandemic compared to during an earlier time-period, before the pandemic. One possible explanation for these decreasing differences over time is that the exposures to loneliness and poor sleep may not be constant over time. Some of the participants experiencing loneliness and sleep problems at baseline may not still have these problems later during follow-up, which could affect the difference in mental health levels between exposed and unexposed. Mental health symptoms over time dichotomized by prepandemic mental health problems were most likely affected by 'regression to the mean'. Our interpretation is that the groups exposed to pre-pandemic loneliness, poor sleep quality and mental health problems did not show unfavourable mental health trajectories during the first months of the COVID-19 pandemic compared to the unexposed groups.

The strengths of this study were firstly that we were able to conduct a natural experiment by investigating the differences in mental health symptoms before and after the pandemic reached Sweden in a longitudinal design, unlike most previous studies with similar aims (15). Secondly, the instruments used for measurements of all variables have good psychometric properties, limiting the risk of misclassification. Finally, we included a large sample of university students from six universities.

We recruited $27 \%$ of eligible students. Therefore, there is a possibility that selection bias influenced our results. However, the baseline pre-pandemic levels of mental health symptoms measured in our cohort were similar to those reported in previous studies of Swedish university students using the same instrument (DASS-21) (24). This suggests that our sample was representative of the mental health status of Swedish university students before the pandemic. The follow-up response rate was $74 \%$ during the first follow-up period (March 14 to June 15, 2020) and 60 \% during the second follow-up period (June 16 
to September 10, 2020). It is possible that the drop-out from the study may have biased our estimates in some direction. However, complete-case sensitivity analyses, only using data from participants who answered during all three time-periods $(n=1049)$, showed results that were very similar to the main analyses (Table 2, eTable 1), indicating that baseline differences between drop-outs and completers did not affect the results significantly.

Our results contrast with much of the previous research into the mental health effects of the COVID-19 pandemic that is generally showing increased levels of mental health problems $(4,15)$. Our results do however dovetail those of Fancourt, Steptoe \& Bu (5) showing decreasing levels of depression and anxiety during lockdown in a large UK cohort, although this study had no measurements before lockdown (5). One explanation for the contrast to much of the previous research may be differences in the impact of COVID-19 in different study populations. It is possible that people in different countries have been affected differently. One reason might be that the spread of the virus has been more severe in some places than others. However, our study was performed in Stockholm, which has had high mortality. Another, more plausible reason may be that different governmental strategies to contain the spread might have had differing impacts on mental health. Sweden's strategy, which has been less restrictive than many other countries, may have had less detrimental effects on mental health. More high-quality research is needed to compare mental health changes between populations during the COVID-19 pandemic, and to evaluate long-term effects.

\section{Conclusions}

Symptom levels of metal health among Swedish university students were relatively stable during the first three months of the pandemic, while there was a decrease during the summer months, probably due to seasonality effects. Students exposed to pre-pandemic loneliness, poor sleep quality or mental health problems showed similar trajectories as students overall, although at higher levels. In conclusion, contrary to our hypothesis, our results do not support a worsening of mental health in Swedish university students during the first months of the COVID-19 pandemic. Nor did not find worse trajectories for students exposed to pre-pandemic loneliness, poor sleep quality or mental health problems.

\section{Abbreviations}

DASS-21: Depression, Anxiety and Stress Scale 21 item version

GEE: General Estimating Equation

GIH: The Swedish School of Health and Sports Sciences

Kl: Karolinska Institutet

KTH: Royal Institute of Technology 
NPH: The Scandinavian College of Naprapathic Manual Medicine

OR: Odds Ratio

PEMPH: Pre-existing mental health problems

PSQI: Pittsburg Sleep Quality Inventory

SCE: Stockholm School of Economics

SHH: Sophiahemmet University

\section{Declarations}

\section{Conflicting interests}

The authors declare that there is no conflict if interests.

\section{Funding}

This research project was funded by the Swedish Research Council for Health, Working Life and Welfare (FORTE), grant number FORTE2018-00402. The project also received financial support from the Public Health Agency of Sweden.

\section{Authors' contributions}

ES was responsible for designing the study with contributions of PC, AR, IJ, MG, LWH, KE and TS. Datacollection was performed by FJ, TS, KE and ES. FJ, ES, PC and SHJ performed the statistical analyses, interpretation, and preparation of the initial manuscript. All authors provided critical revisions of the intellectual content.

\section{Availability of data and materials}

The dataset generated and analyzed during the current study are not publicly available due to secondary confidentiality and privacy of the participants.

\section{Acknowledgements}

We would like to thank Torsten Wrigley, Felix Sjöstrand, Madeleine Naidoo Bjørnstad, Louise Bergman, Rebecca Lindroth, Dan Tanaka, Hanna Ryding and Hjalmar Kyle for their contributions to the project.

\section{References}

1. Holmes EA, O'Connor RC, Perry VH, Tracey I, Wessely S, Arseneault L, et al. Multidisciplinary research priorities for the COVID-19 pandemic: a call for action for mental health science. Lancet Psychiatry. 
2020;7(6):547-60.

2. Ibrahim AK, Kelly SJ, Adams CE, Glazebrook C. A systematic review of studies of depression prevalence in university students. J Psychiatr Res. 2013 Mar;47(3):391-400.

3. Rotenstein LS, Ramos MA, Torre M, et al. Prevalence of Depression, Depressive Symptoms, and Suicidal Ideation Among Medical Students: A Systematic Review and Meta-Analysis. JAMA: Journal of the American Medical Association 2016; 316(21): 2214-36.

4. Thombs BD, Bonardi O, Rice DB, Boruff JT, Azar M, He C, et al. Curating evidence on mental health during COVID-19: A living systematic review. Journal of psychosomatic research. 2020;133:1101-13.

5. Fancourt D, Steptoe A, Bu F. Trajectories of anxiety and depressive symptoms during enforced isolation due to COVID-19 in England: a longitudinal observational study. The Lancet Psychiatry. 2020 (In press).

6. Elmer T, Mepham K, Stadtfeld C. Students under lockdown: Comparisons of students' social networks and mental health before and during the COVID-19 crisis in Switzerland. PLoS One. 2020;15(7):e0236337.

7. Huckins JF, daSilva AW, Wang W, Hedlund E, Rogers C, Nepal SK, et al. Mental Health and Behavior of College Students During the Early Phases of the COVID-19 Pandemic: Longitudinal Smartphone and Ecological Momentary Assessment Study. Journal of medical Internet research. 2020;22(6):e20185.

8. Fried El, Papanikolaou F, Epskamp S. Mental Health and Social Contact During the COVID-19 Pandemic: An Ecological Momentary Assessment Study. PsyArXiv. 2020. DOI: https://doi.org/10.31234/osf.io/36xkp

9. The Public Health Agency of Sweden. Ny fas kräver nya insatser mot covid-19 https://www.folkhalsomyndigheten.se/nyheter-och-press/nyhetsarkiv/2020/mars/ny-fas-kraver-nyainsatser-mot-covid-19/: Public Helath Agency of Sweden; 2020.

https://www.folkhalsomyndigheten.se/nyheter-och-press/nyhetsarkiv/2020/mars/ny-fas-kraver-nyainsatser-mot-covid-19/. (2020, accessed 23 December 2020).

10. The Public Health Agency of Sweden. Lärosäten och gymnasieskolor uppmanas nu att bedriva distansundervisning 2020. https://www.folkhalsomyndigheten.se/nyheter-ochpress/nyhetsarkiv/2020/mars/larosaten-och-gymnasieskolor-uppmanas-nu-att-bedrivadistansundervisning/. (2020, accessed 23 December 2020).

11. The Public Health Agency of Sweden. Beteende, oro och informationsbehov: Genomförda och pågående undersökningar under covid-19. Report, The Public Health Agency of Sweden. Report no. 20101, 24 June 2020.

12. The Academy of Medical Sciences. 2020. https://acmedsci.ac.uk/file-download/99436893 (accessed December 10,2020 ).

13. Cacioppo JT, Hawkley LC, Thisted RA. Perceived social isolation makes me sad: 5-year cross-lagged analyses of loneliness and depressive symptomatology in the Chicago Health, Aging, and Social Relations Study. Psychol Aging. 2010; 25(2): 453-63. 
14. Wang J, Mann F, Lloyd-Evans B, Ma R, Johnson S. Associations between loneliness and perceived social support and outcomes of mental health problems: a systematic review. BMC psychiatry 2018; 18(1): 156.

15. Vindegaard N, Eriksen Benros M. COVID-19 pandemic and mental health consequences: Systematic review of the current evidence. Brain Behav Immun. 2020. https://doi.org/10.1016/j.bbi.2020.05.048

16. Sivertsen B, Vedaa $\emptyset$, Harvey AG, Glozier N, Pallesen S, Aarø LE, et al. Sleep patterns and insomnia in young adults: A national survey of Norwegian university students. J Sleep Res. 2019; 28(2):e12790.

17. Franceschini C, Musetti A, Zenesini C, Palagini L, Scarpelli S, Quattropani MC, et al. Poor Sleep Quality and Its Consequences on Mental Health During the COVID-19 Lockdown in Italy. Frontiers in psychology. 2020;11:574475.

18. Walker MP. The role of sleep in cognition and emotion. Ann N Y Acad Sci. 2009 Mar;1156:168-97.

19. Zohar D, Tzischinsky O, Epstein R, Lavie P. The effects of sleep loss on medical residents' emotional reactions to work events: a cognitive-energy model. Sleep. 2005 Jan;28(1):47-54.

20. Yao H, Chen JH, Xu YF. Patients with mental health disorders in the COVID-19 epidemic. Lancet Psychiatry. 2020;7(4):e21.

21. Cuijpers P, Smit F. Subthreshold depression as a risk indicator for major depressive disorder: a systematic review of prospective studies. Acta Psychiatr Scand. 2004;109(5):325-31.

22. Lee YY, Stockings EA, Harris MG, Doi SAR, Page IS, Davidson SK, et al. The risk of developing major depression among individuals with subthreshold depression: a systematic review and meta-analysis of longitudinal cohort studies. Psychol Med. 2019;49(1):92-102.

23. Henry JD, Crawford JR. The short-form version of the Depression Anxiety Stress Scales (DASS-21): construct validity and normative data in a large non-clinical sample. Br J Clin Psychol. 2005 Jun;44(Pt 2):227-39

24. Alfonsson S, Wallin E, Maathz P. Factor structure and validity of the Depression, Anxiety and Stress Scale-21 in Swedish translation. J Psychiatr Ment Health Nurs. 2017;24(2-3):154-62.

25. Lovibond S, Lovibond P. Manual for the depression anxiety stress scales (DASS). Psychology Foundation Monograph. Sydney, Australia: University of New South Wales 1993.

26. Ronk FR, Korman JR, Hooke GR, Page AC. Assessing clinical significance of treatment outcomes using the DASS-21. Psychol Assess. 2013 Dec;25(4):1103-10.

27. Hughes ME, Waite LJ, Hawkley LC, Cacioppo JT. A Short Scale for Measuring Loneliness in Large Surveys: Results From Two Population-Based Studies. Res Aging. 2004;26(6):655-72.

28. Steptoe A, Shankar A, Demakakos $P$, Wardle J. Social isolation, loneliness, and all-cause mortality in older men and women. Proc Natl Acad Sci USA. 2013;110(15):5797-801.

29. Carpenter JS, Andrykowski MA. Psychometric evaluation of the Pittsburgh Sleep Quality Index. J Psychosom Res. 1998;45(1):5-13.

30. Buysse DJ, Reynolds CF, 3rd, Monk TH, Berman SR, Kupfer DJ. The Pittsburgh Sleep Quality Index: a new instrument for psychiatric practice and research. Psychiatry Res 1989; 28(2): 193-213. 
Figures

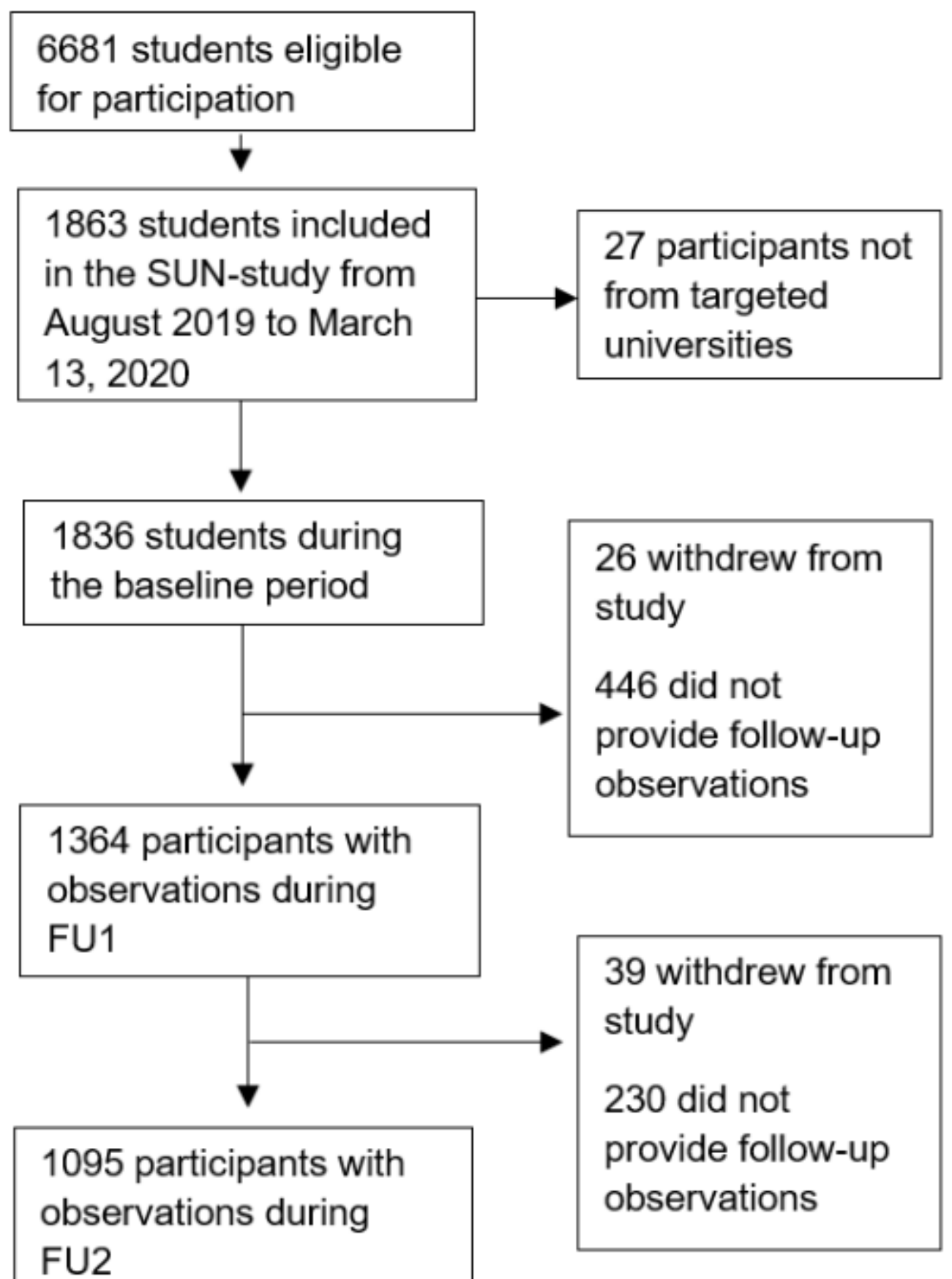

\section{Figure 1}

Flow chart of inclusion of participants 


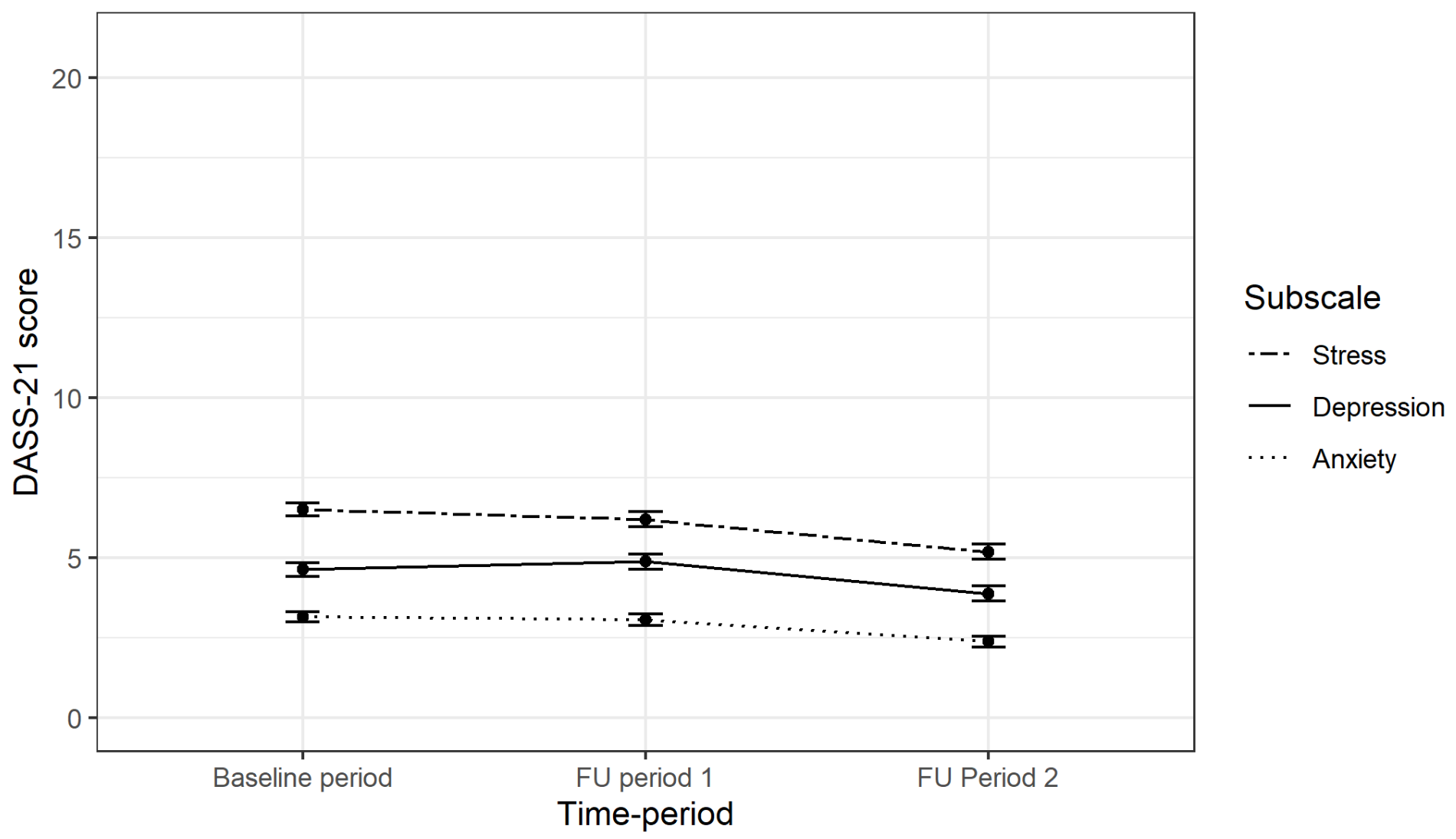

Figure 2

Mean DASS-21 scores over the three time-periods. 


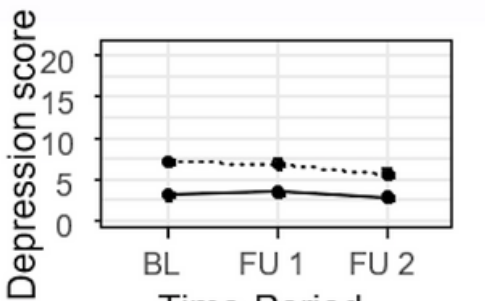

Time-Period

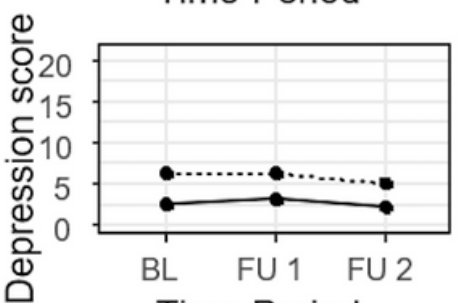

Time-Period

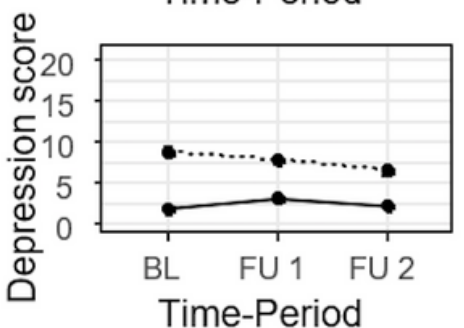

Time-Period

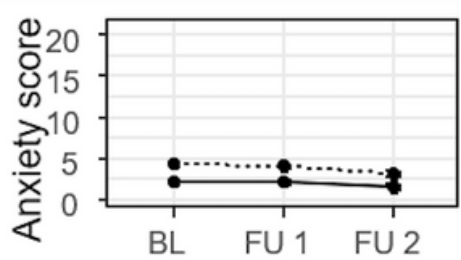

Time-Period

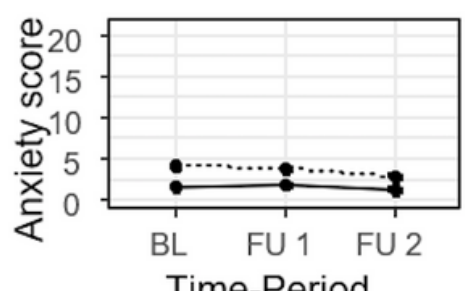

Time-Period

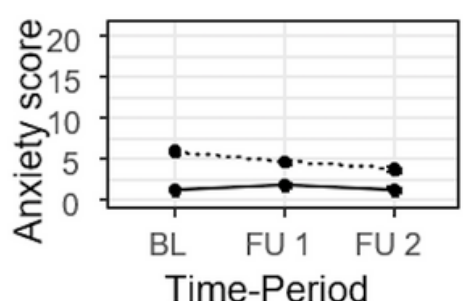

Time-Period
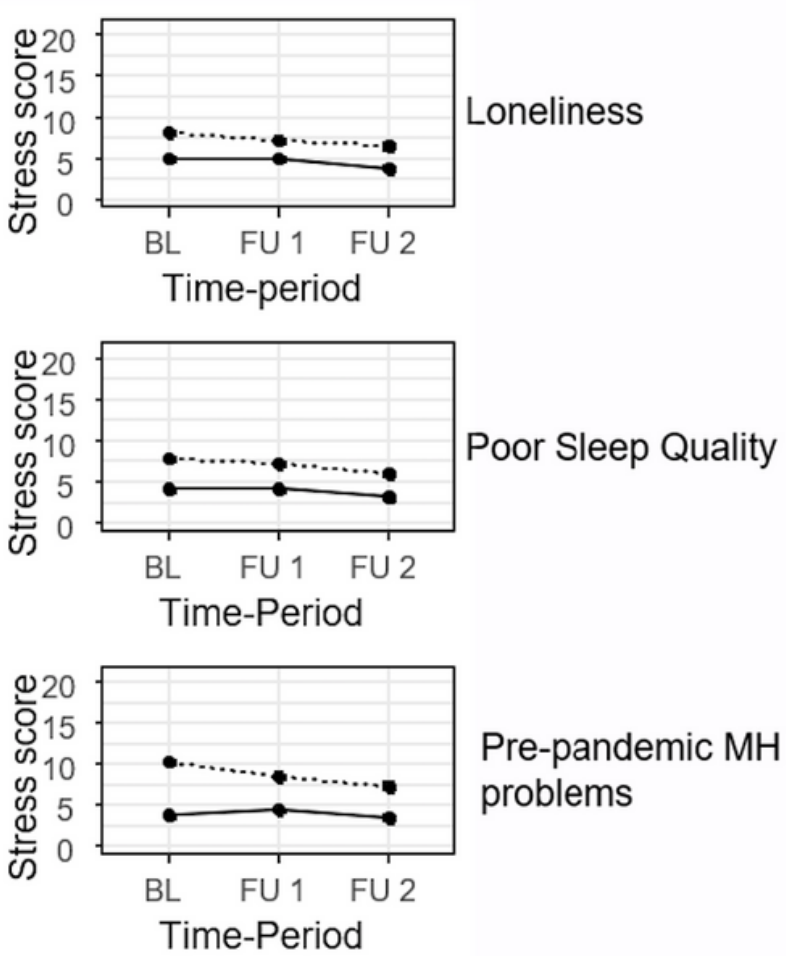

Figure 3

Estimated mean of DASS-21 scores over time stratified by exposures. Graphs of estimated means on DASS-21 from GEE models stratified by loneliness, sleep quality and pre-pandemic mental health $(\mathrm{MH})$ problems. Adjusted for gender and age.

\section{Supplementary Files}

This is a list of supplementary files associated with this preprint. Click to download.

- eFigure1Timelineofinclusion.pptx

- eFigure2Graphsovertimebyexposuresaugtodec.docx

- eTable1.GEEcoefficientcompletecases.docx 